\title{
VOZES E MEMÓRIA NO/DO COTIDIANO ESCOLAR: O PRIMEIRO DIA DE ESCOLA E DE AULA DE ACADÊMICOS DE EDUCAÇÃO FÍSICA EM SITUAÇÃO DE ESTÁGIO CURRICULAR SUPERVISIONADO
}

\author{
VOCES Y MEMORIA EN EL/DEL COTIDIANO ESCOLAR: EL PRIMER DÍA DE \\ ESCUELA Y DE CLASE DE ACADÉMICOS DE EDUCACIÓN FÍSICA EN \\ SITUACIÓN DE PRÁCTICA CURRISULAR SUPERVISADA
}

VOICES AND MEMORY IN/OF DAILY SCHOOL: THE FIRST DAY OF SCHOOL AND OF THE CLASS OF ACADEMICS PHYSICAL EDUCATION IN SITUATION OF SUPERVISED

\author{
Hugo Norberto KRUG ${ }^{1}$ \\ Rodrigo de Rosso KRUG ${ }^{2}$ \\ Cassiano TELLES ${ }^{3}$ \\ Victor Julierme Santos da CONCEIÇÃO ${ }^{4}$
}

RESUMO: O estudo objetivou dar voz aos acadêmicos da licenciatura em Educação Física do CEFD/UFSM para relatar suas experiências vividas no primeiro dia de escola e de aula por ocasião do Estágio Curricular Supervisionado (ECS). A metodologia caracterizou-se pela abordagem qualitativa de pesquisa usando a abordagem biográfica como método e trabalhando com relatos (auto)biográficos escritos, analisados à luz da identificação de significados. Participaram 20 estagiários. Concluímos que o processo de inserção dos estagiários na escola constituiu-se em momento importante para o ECS, devido às implicações dele decorrentes, pois se o ambiente e as recepções não forem adequadas a tendência é de potencialização das dificuldades.

PALAVRAS-CHAVE: Educação física. Formação de professores. Estágio curricular supervisionado. Cotidiano escolar. Narrativas.

RESUMEN: El estudio tiene el objetivo dar voz a los académicos del Profesorado en Educación Física del CEFD/UFSM, para relatar sus experiencias vividas en el primer día de escuela y de clase en el momento de la Práctica Curricular Supervisada (PCS). La metodologia se caracterizó por el abordaje de investigación cualitativo, por medio del enfoque biográfico como método y centrándose en relatos (auto)biográficos escritos, analizados a la luz de la identificación de significados. Participaron de la investigación 20 alumnos de la Práctica. Concluímos que el proceso de inserción de esos alumnos en

\footnotetext{
${ }^{1}$ Doutor em Educação - Doutor em Ciência do Movimento Humano - Professor do Programa de PósGraduação em Educação - Professor do Programa de Pós-Graduação em Educação Física. UFSM Universidade Federal de Santa Maria Santa Maria - Rio Grande do Sul - Brasil. 97.115-900 hnkrug@bol.com.br.

${ }^{2}$ Doutorando em Ciências Médicas. UFSC - Universidade Federal de Santa Catarina -Florianópolis Santa Catarina - Brasil. 88040-970 - rodkrug@bol.com.br.

${ }^{3}$ Mestrando em Educação Física. UFSM - Universidade Federal de Santa Maria - Santa Maria - Rio Grande do Sul - Brasil.97.115-900 - telleshz@yahoo.com.br .

${ }^{4}$ Doutor em Ciências do Movimento Humano. UNESC - Universidade do Extremo Sul Catarinense Criciúma - Santa Catarina - Brasil. 90040-060 - victorjulierme@ yahoo.com.br.
} 
la escuela se constituye en un momento importante para su Práctica Curricular Supervisada (PCS), debido a las implicaciones decorrentes de ella, pues si el ambiente y las recepciones no son adecuadas la tendencia es de potenciar las dificultades.

PALABRAS CLAVE: Educación física. Formación de profesores. Práctica curricular supervisada. Cotidiano escolar. Narrativas.

ABSTRACT: The study aimed to give voice the academics of degree in Physical Education of the CEFD/UFSM for to relate their experiences lived in the first day of school and of class by occasion of Supervised (ECS). The methodology was characterized by approach qualitative research using the biographical approach with method and working with relation (self) biographical writings, analyzed in light of the identification of meanings. Was participated 20 trainees. We conclude that the process of insertion of academics in school constituted in a important moment for the ECS, due the implications its arising, if the environment and receptions do not suit trend is of potentiation of the difficulties.

KEYWORDS: Physical education. Teacher formation. Supervised dayli school. Narratives.

\section{Considerações iniciais}

Segundo Marques e Krug (2010), o meio educacional, bem como o contexto da formação de professores e as diversas peculiaridades que compõem os cursos de licenciaturas, nos permitem e nos instigam a desenvolver diversos estudos e pesquisas a fim de contribuir com nossa própria formação, assim como de fomentar questionamentos e trocas com os demais profissionais da educação e em especial da Educação Física.

Assim, neste amplo cenário de possibilidades de estudos e pesquisas que são os cursos de licenciaturas, um dos mais importantes componentes curriculares e de indiscutível relevância para a formação do licenciando, de acordo com Marques; Ilha e Krug (2009), é a disciplina de Estágio Curricular Supervisionado (ECS). Para Miranda (2008), o ECS, nos cursos de formação de professores, é um momento único em que o acadêmico tem a oportunidade de interagir com os alunos e também enfrentar os desafios do cotidiano escolar, bem como é o espaço para reflexão crítica e a formação da identidade docente. O estágio é, portanto, uma ação educativa e social, uma forma de intervir na realidade.

Em meio a esta realidade existe a preocupação com o primeiro dia de escola e de aula no ofício da docência pré-profissional (ECS), pois, segundo Fortunato; Catunda e Reigota (2013), reconhecer o primeiro dia da vida escolar de futuros professores é, 
atualmente, uma inquietação de quem se envolve com a disciplina de ECS, buscando alternativas para uma formação de qualidade para os acadêmicos.

Desta forma, diante do amplo quadro de cursos de licenciaturas e da disciplina de Estágio Curricular Supervisionado, focamos o nosso interesse investigativo na Universidade Federal de Santa Maria (UFSM) e, particularmente, no ECS III (Séries/Anos Iniciais do Ensino Fundamental) do curso de licenciatura em Educação Física do Centro de Educação Física e Desportos (CEFD), pois concordamos com Ivo e Krug (2008) de que estudar o quê e quem envolve essa disciplina é tarefa daqueles que se preocupam com uma formação de qualidade para os futuros docentes.

Convém salientar que a grade curricular (CEFD, 2005) do curso de licenciatura em Educação Física do CEFD/UFSM proporciona o Estágio Curricular Supervisionado I, II e III nos $5^{\circ}, 6^{\circ}$ e $7^{\circ}$ semestres do mesmo, realizados respectivamente no Ensino Médio, nas Séries/Anos Finais do Ensino Fundamental e nas Séries/Anos Iniciais do Ensino Fundamental, com carga de 120 horas destinadas a cada estágio, somando-se a essas 360 horas mais 45 horas de Seminário em Estágio Curricular Supervisionado, no $8^{\circ}$ semestre do curso, totalizando então 405 horas.

Consequentemente, considerando este contexto, elaboramos a seguinte questão problemática norteadora deste estudo: Como foi o primeiro dia de escola e de aula de acadêmicos da licenciatura em Educação Física do CEFD/UFSM em situação de Estágio Curricular Supervisionado III?

Desta forma, partimos do pressuposto destacado por Pimenta e Lima (2004) de que o ECS é um retrato vivo da prática docente e que o professor-aluno (estagiário) tem muito a dizer, a ensinar, expressando sua realidade, a de seus colegas de profissão e de seus alunos, que no mesmo tempo histórico vivenciam os mesmos desafios e as mesmas crises na escola e na universidade.

Neste direcionamento de ideia, nos reportamos a Fortunato; Catunda e Reigota (2013), que acreditam que a memória carrega experiências que podem ajudar a compreender alguns germens vocativos, que levam as pessoas a assumir o trabalho ético e político de lecionar. Já segundo Horn e Oliveira (1998 apud KRUG; IVO; KRUG, 2009), a memória é marcada por situações e experiências de vida, onde se inclui o cotidiano escolar. Também citamos Alves (2001), que diz que o cotidiano escolar é um lugar multifacetado, fluído, prenhe de possibilidades para transformações, desenvolvimentos, aprendizagens e vínculos. 
Assim, nesta investigação, utilizamo-nos das narrativas que tiveram como ponto de partida as lembranças do primeiro dia de vida escolar e da primeira aula ministrada, remetendo os sujeitos (acadêmicos em situação de ECS) às vivências mais recentes no tempo (o ECS III). Segundo Fortunato; Catunda e Reigota (2013), as narrativas são produzidas como testemunhos que refletem expressões vivas da escola como ambiente plurifacetado: desejado, imaginado, sonhado e/ou temido. Ainda os autores supracitados dizem que uma das formas de recuperar memórias é aquela que parte de um exercício livre de narrar sobre experiências diretas, sem impor tempo ou quantidade de texto limites para contar sobre o que é lembrado do primeiro contato com a escola e os alunos.

Diante do exposto, o objetivo geral deste estudo foi dar voz aos acadêmicos da licenciatura em Educação Física do CEFD/UFSM para relatar suas experiências vividas no primeiro dia de escola e de aula por ocasião do Estágio Curricular Supervisionado III (Série/Anos Iniciais do Ensino Fundamental).

Justificamos a realização desta investigação ao citarmos Krug e Krug (2012), que destacam a grande importância de que o ECS seja mais estudado, mais esclarecido e divulgado os seus impactos na formação, para que os futuros professores, particularmente de Educação Física, estejam melhores preparados para enfrentá-lo, bem como, quando ingressarem na carreira docente, não sofrerem o impacto do choque com a realidade escolar, o que dificulta a obtenção do sucesso pedagógico.

\section{Procedimentos metodológicos}

Apoiamos os procedimentos metodológicos desta investigação numa abordagem qualitativa de pesquisa que, segundo Bodgan e Biklen (1994), tem o ambiente natural como fonte direta dos dados e o pesquisador como instrumento-chave. Entretanto, como os problemas são estudados no ambiente em que eles ocorrem naturalmente, sem qualquer eventual manipulação intencional do pesquisador, esse tipo de estudo também pode ser chamado de 'naturalístico'. Ainda é destacado pelos autores que os dados coletados são predominantemente descritivos, mas a preocupação dos investigadores com o processo é muito maior do que simplesmente com o resultado e o produto, sendo o significado a preocupação essencial. 
Assim, tendo em vista que a pesquisa qualitativa abre espaços para uma investigação flexível, utilizamo-nos da abordagem biográfica como método de pesquisa, trabalhando com relatos (auto)biográficos escritos (narrativas escritas).

Segundo Moita (1992), abordagem biográfica é uma expressão genérica ligada à história de vida.

Já (auto)biografia, de acordo com Abrahão (2004, p.202), “é uma forma de história auto-referente, portanto plena de significado, em que o sujeito se desvela para si e se desvela para os demais". A autora coloca ainda que as (auto)biografias são construídas por narrativas, onde se desvelam trajetórias de vida com a qualidade de possibilitar a auto-compreensão, o conhecimento de si, em que as pessoas estão em constante processo de auto-conhecimento.

Para Reigota (1999, p.80) "as narrativas (escrita, oral, visual, corporal) não são mentiras, mas uma forma criativa [...] de organizar e comunicar situações vividas e imaginadas".

Na visão de Cunha (1997) as narrativas têm sido utilizadas na pesquisa qualitativa como instrumento de construção de dados e também são consideradas como procedimento de formação, porque ao mesmo tempo em que o indivíduo organiza as suas ideias para fazer determinado relato, quer por escrito ou oral, reconstrói suas experiências para a re-orientação do presente. Dessa maneira, as narrativas são utilizadas tanto como procedimento de pesquisa quanto de formação, pois permitem a produção de novos conhecimentos.

Em nosso estudo utilizamos a narrativa escrita como instrumento metodológico (OLIVEIRA, 2006; ANDRÉ, 2005; JOSSO, 2002).

As narrativas foram colhidas com o objetivo de compreender como as experiências ou vivências do primeiro contato com a escola aconteceram. Nesse sentido, citamos Fortunato; Catunda e Reigota (2013) que colocam que, nas narrativas, com suas vozes pulsantes, manifestam-se expressões sensíveis das trajetórias pautadas pela pluralidade/diversidade de um universo multifacetado e dinâmico que é o cotidiano escolar.

As questões norteadoras para a produção das narrativas escritas foram: a) Descreva como foi o seu primeiro dia de escola; e, b) Descreva como foi a sua primeira aula ministrada.

Para facilitar a livre expressão dos envolvidos na pesquisa, buscando eliminar o receio de realizar os registros, foi-lhes sugerido a utilização de pseudônimos (na 
verdade números). Ainda, não tinha nenhum limite de páginas nem tempo imposto, já que o propósito era a recuperação de suas memórias não como registro histórico ou quantitativo das experiências vividas, mas explorá-las de forma simbólica e afetiva.

As narrativas escritas foram analisadas à luz da identificação de significados, conforme o destacado por Oliveira (2006), André (2005) e Josso (2002).

Para este estudo, foram selecionadas algumas das narrativas (nomeadas como vozes), que surgiram como chamados no fluxo presente, muito mais do que lembranças de um passado não muito distante.

Após a seleção das narrativas, partimos para uma descrição de como o primeiro dia de contato com a escola e a primeira aula resultou em diferentes formas de vivenciar (agenciar) o processo educativo e formativo.

Participaram deste estudo vinte (20) acadêmicos da licenciatura em Educação Física do CEFD/UFSM, matriculados na disciplina de Estágio Curricular Supervisionado III (Séries/Anos Iniciais do Ensino Fundamental). A escolha dos participantes deu-se de forma intencional, sendo a disponibilidade dos mesmos o fator determinante para ser considerado colaborador da pesquisa.

Quanto aos aspectos éticos vinculados às pesquisas científicas, destacamos que todos os participantes assinaram o Termo de Consentimento Livre e Esclarecido (TCLE) e as suas identidades foram preservadas (numeração de $\mathbf{1}$ a $\mathbf{2 0}$ ).

\section{Resultados e discussões}

O quadro de análise interpretativa das narrativas escritas dos estagiários estudados foi elaborado de acordo com o objetivo geral desta pesquisa. E, nesse sentido, procuramos, de acordo com Ferraroti (apud MOITA, 1992, p.117): “ordenar, compreender sem desnaturar, sem violentar, sem sobre-impor um esquema préestabelecido". Também é importante salientar que ao selecionarmos algumas vozes dentre as inúmeras que compuseram o coletado, fazemos apenas o exercício de lançar luz sobre determinadas vozes, sem jamais desconsiderar outras, bem como esgotar as complexas potencialidades das mesmas.

Desta forma, considerando o objetivo do estudo, a análise das narrativas escritas foi realizada a partir de dois (2) grandes eixos: o primeiro dia de escola e o primeiro dia de aula. 


\section{O primeiro dia de escola na percepção de acadêmicos de Educação Física em situação de Estágio Curricular Supervisionado}

Pela análise das narrativas escritas podemos constatar que todos os (vinte) estagiários 'foram muito bem recepcionados pela escola, isto é, pela equipe diretiva, bem como pelos professores das turmas de estágio'. Esse fato contraria o destacado por Panis (2006), que diz que nem sempre estagiários são bem recebidos pela escola, pois parecem não estar preparadas para receberem estagiários, não os apóiam e os vêem como um estorvo ao trabalho cotidiano da escola.

E, sobre esta recepção destacamos algumas vozes a seguir: "Fui aceito com muito respeito tanto pela diretora como pela professora de classe dando o máximo de atenção [...]" (Estagiário 1); "Fácil! O recebimento foi de braços abertos, tanto da equipe diretiva quanto da professora. [...]. Rapidamente me senti mais à vontade para o desenvolvimento do estágio" (Estagiário 3); "Quando cheguei, no primeiro dia, procurando estágio fui bem recebida pela coordenação da escola, a supervisora adorou por ter ido lá procurar estágio. A professora da turma também gostou [...]" (Estagiário 5); "Foi muito tranqüila. A supervisora me recebeu muito bem, foi muito atenciosa. A professora da turma, no primeiro dia mesmo sem saber que estagiaria com ela, me recebeu muito bem. [...]. Os demais funcionários da escola, mesmo não sabendo da minha função, me trataram muito bem" (Estagiário 8); "Fui muito bem acolhido na escola, tanto por parte dos professores e direção quanto pelos funcionários [...]" (Estagiário 10); "Meu ingresso na escola foi muito bom, [...] a receptividade por parte da coordenação e direção foram ótimos [...]" (Estagiário 12); "Tive uma excelente recepção, por todos os setores da escola, desde a equipe diretiva até [...] e da professora da turma. Sendo que a professora da turma concedeu-me respaldo para que eu pudesse realizar meu trabalho da melhor forma possível [...]” (Estagiário 15); e, “A escola se mostrou bastante receptiva, tanto por parte da direção como da professora de currículo e da coordenadora pedagógica [...]”" (Estagiário 20).

Assim, percebemos que todas estas vozes dos estagiários destacaram a importância dos gestores da escola para uma boa recepção dos mesmos. Segundo Marcellos (2009), o gestor, representado pelo diretor da escola, é o grande articulador da escola e, deve esforçar-se por criar canais adequados de comunicação e interação e garantir o alcance dos objetivos da escola, mantendo o bom clima entre as pessoas que fazem parte da comunidade escolar e local. 
A autora acrescenta ainda que o gestor é co-responsável pelo sucesso ou fracasso de uma boa comunicação e, consequentemente, por uma relação interpessoal de qualidade, pois é o articulador do processo e o incentivador do trabalho coletivo. Ao iniciar o processo de coordenação de um grupo, o gestor precisa dar mais informações claras, organizar o tempo, o espaço, a rotina, as tarefas para facilitar o processo de inclusão das pessoas na equipe.

Já quanto à recepção dos estagiários pelos alunos das turmas de estágio, praticamente para todos (dezenove) 'foi muito boa', isto na apresentação dos mesmos.

Algumas vozes dos estagiários foram as seguintes: "[...] os alunos me receberam muito bem [...]" (Estagiário 2); “[...] os alunos me receberam de bracos abertos [...]" (Estagiário 6); “[...] os alunos gostaram muito de mim [...]” (Estagiário 7); “[...] os alunos foram receptivos e empolgados [...]" (Estagiário 9); "Fui bem acolhido [...] pelos alunos" (Estagiário 11); e, “[...]. Os alunos eram muito queridos, vinham me abraçar e me beijar o tempo todo [...]" (Estagiário 13).

Assim, pelas vozes dos estagiários podemos constatar um bom clima receptivo proporcionado pelos alunos. Nesse sentido, podemos inferir que essa boa recepção aos estagiários pode estar relacionada ao fato de que "a grande maioria dos alunos gostam das aulas de Educação Física na escola" (SILVA; KRUG, 2005, p.81).

Entretanto, para somente um estagiário a 'recepção dos alunos da turma de estágio não foi boa'. O motivo alegado para tal fato foi de que "[...] os alunos já estavam acostumados com a professora de classe, isto é, com o sistema de deixá-los à vontade nas aulas de Educação Física para fazerem o que quisessem [...]" (Acadêmico 18). Essa situação está em consonância com Krug (1996) de que o processo de aceitação entre pessoas supõe uma atitude de escuta e empatia, pois implica em viver junto, em partilhar o cotidiano, a utilização do tempo e do espaço: ouvir, observar, compartilhar e interagir.

Desta forma, após analisar todas as vozes dos estagiários sobre o primeiro dia de escola, podemos inferir que a recepção e/ou acolhimento, sem dúvida alguma, aconteceu de formas diferentes para cada um deles, sendo de dois tipos, um bom e outro não tão bom. Esse fato pode ser considerado normal, já que esta recepção/acolhimento depende de questões culturais da escola e também do grupo de profissionais que fazem parte da escola, a gestão escolar ou os próprios alunos.

Neste direcionamento de temática, isto é, o primeiro dia de escola ou em outras palavras o início da imersão na escola, consideramos necessário citar Lave e Wenger 
(1991 apud KRUG et al., 2012), que colocam que a necessidade de aprendizagem profissional que ocorre em espaços reais de exercício profissional, principalmente pela imersão numa comunidade educativa (escola) durante o ano letivo é peça fundamental na formação de futuros professores, e é nesse contato que o estagiário conhece os contornos da profissão, tornando-se, pouco a pouco, um integrante dessa comunidade educativa, denominada de comunidade prática.

\section{O primeiro dia de aula na percepção de acadêmicos de Educação Física em situação de Estágio Curricular Supervisionado}

Pela análise das narrativas escritas podemos constatar que todos os (vinte) estagiários manifestaram que 'tinham como expectativa a possibilidade de realização de um bom trabalho com os alunos', quando do início da primeira aula na escola. Esse fato está em concordância com o estudo de Krug e Krug (2011), que constataram que todos os acadêmicos antes de iniciarem o ECS da licenciatura em Educação Física do CEFDIUFSM tinham boas intenções e estavam dispostos a desenvolverem um trabalho de qualidade.

Eis algumas vozes dos estagiários que ilustram suas expectativas: "Pretendo realizar um bom trabalho [...]" (Estagiário 4); "Espero desenvolver boas aulas com os alunos [...]” (Estagiário 14); “[...]. Creio que os alunos vão gostar das minhas aulas [...]" (Estagiário 16); e, “[...]. Apesar dos alunos terem tido uma certa resistência à minha participação como professor de Educação Física da turma, tenho plena certeza de que eles gostarão das aulas e de mim com o passar das aulas" (Estagiário 18).

Entretanto, com o início e o desenvolvimento da primeira aula, notamos em várias (doze) narrativas escritas (Estagiários: $2 ; 4 ; 6 ; 10 ; 11 ; 13 ; 14 ; 15 ; 17 ; 18 ; 19$ e 20) 'o surgimento de tensões com os alunos'. Segundo Luft (2000) tensão é o estado do que é ou se apresenta tenso, é um desacordo nas relações entre partes.

E este fato pode ser representado pela voz do estagiário 19: "Na primeira aula fiquei muito tenso porque os alunos ficaram na retranca, isto é, não se entusiasmaram com as atividades, não participaram [...]".

As narrativas escritas também apontaram que estas tensões foram originadas por 'dificuldades' que apareceram no decorrer da primeira aula. Para Luft (2000), dificuldade é uma situação crítica, aquilo que é difícil, um obstáculo. Assim, o principal obstáculo manifestado por vários (doze) estagiários $(2 ; 4 ; 6 ; 10 ; 11 ; 13 ; 14 ; 15 ; 17 ; 18$; 19 e 20) foram a 'agitação dos alunos' e a 'indisciplina dos alunos'. Esse fato é 
corroborado por Krug (2011) que salienta que a agitação e a indisciplina dos alunos são algumas das principais dificuldades que os acadêmicos da licenciatura em Educação Física do CEFD/UFSM enfrentam por ocasião do ECS que interferem em suas práticas pedagógicas. Também Pimenta e Lima (2004) destacam que no início das atividades docentes são comuns as denúncias dos estagiários sobre problemas relativos à indisciplina dos alunos.

Isto pode ser notado em algumas vozes dos estagiários a seguir: "Acredito que minha primeira aula foi um tanto conturbada em virtude de a escola não possuir a chave da sala de material do ginásio e ter que pegar as chaves de outra sala para utilizar materiais. A professora demorou a descer com os alunos. Troquei a ordem das atividades e deixei o pega-pega por último, deixando assim os alunos agitados" (Estagiário 6); “[...] foi perceptível que alguns alunos são muito indisciplinados na aula [...]" (Estagiário 11); "[...] os alunos são muito agitados e é difícil deles prestarem tenção e ficarem quietos" (Estagiário 13); "Minha primeira aula foi difícil porque os alunos bagunçaram muito. Não paravam de se empurrar, se bater [...]" (Estagiário 17); e, “A minha primeira aula [...] em virtude dos alunos serem agitados se fez necessário algumas interrupções para chamar à atenção deles [...]" (Estagiário 20).

Assim, em virtude deste contexto, do surgimento de tensões com os alunos, de dificuldades no desenvolvimento da primeira aula, alguns (cinco) estagiários (6; 11; 13; 17 e 20) relataram que 'sentiram medo' para a sequência das aulas. Luft (2000) coloca que medo é uma perturbação resultante da idéia de um perigo real ou aparente ou ainda da presença de alguma coisa estranha ou perigosa. É um pavor, susto, temor. Esse fato está em concordância com Pimenta e Lima (2004) que dizem que os relatórios de estágio mostram que a primeira revelação de muitos estagiários é sobre o medo no convívio com o espaço escolar. Também Krug e Krug (2012) colocam que o medo é um sentimento que aparece para alguns acadêmicos da licenciatura em Educação Física do CEFD/UFSM em situação de estágio.

Para ilustrar esta situação citamos algumas vozes dos estagiários que denunciaram a sua ocorrência: "Na primeira aula tive medo [...]" (Estagiário 6); "Fiquei com muito medo de dar aula para a turma de alunos considerando os problemas da primeira aula" (Estagiário 11); "A partir das dificuldades que tive na primeira aula senti muito medo do que pode vir nas próximas aulas [...]" (Estagiário 
17); e, “[...]. Quando me deparei com certos problemas com os alunos senti medo para a sequência do estágio" (Estagiário 20).

Consequentemente, estas vozes caracterizaram a confrontação inicial dos estagiários, em sua primeira aula, com a complexidade da situação real da atuação docente, isto é, a distância de suas expectativas de uma boa atuação e a realidade cotidiana das escolas.

Desta forma, neste quadro de complexidade da docência, alguns (cinco) estagiários $(6 ; 11 ; 13 ; 17$ e 18) declararam-se em 'crise'. Segundo Luft (2000), crise é a conjuntura de incertezas e dificuldades. Essa situação é corroborada por Ilha; Krug e Krug (2009) que dizem que crises podem ocorrer em épocas ou momentos variados do estágio e são consequências de fatores circunstanciais. Todavia, destacam que a ocorrência de crise(s) é intensamente declarada no início do estágio.

Sobre este fato destacamos as seguintes vozes: "Em conseqüência do que ocorreu na primeira aula, a dificuldade de controlar os alunos, entrei em crise. Pensei: como vou fazer para conseguir controlar os alunos?" (Estagiário 11); "Bah, fiquei apavorado, em crise mesmo, com os alunos que tenho! O que fazer? Nem sei o que pensei!" (Estagiário 17); e, “É não foi fácil a primeira aula! Os alunos são muito agitados. O que fazer? É neste dia, entrei em crise" (Estagiário 20).

Consequentemente, esta situação de crise(s) levou alguns (três) estagiários (11; 17 e 20) a manifestarem o 'surgimento de um sentimento de insegurança' no desenvolvimento de sua primeira aula. De acordo com Luft (2000) insegurança é a falta de segurança.

Eis as vozes: “[...] as atividades previstas para a aula não saíram como o que previ e isto gerou uma insegurança no desenrolar da aula [...]” (Estagiário 11); “[...] não consegui desenvolver as atividades planejadas e fiquei muito inseguro [...]" (Estagiário 17); e, “[...] nada deu certo na aula [...] cheguei a pensar que não tinha capacidade para dar aula. Fiquei inseguro [...]" (Estagiário 20).

Estas vozes estão em concordância com o colocado por Krug (2010a) de que a insegurança na docência é um dos fatos marcantes do ECS na percepção dos acadêmicos da licenciatura em Educação Física do CEFD/UFSM.

Entretanto, é necessário citar Krug et al. (2013), que dizem que no processo de formação inicial o sentimento de insegurança é recorrente, pois o estagiário está começando a dar significado à sua prática pedagógica. 
Em virtude destas situações anteriormente descriminadas levam-nos a inferir que, já no primeiro dia de aula, 'surgiu um quadro de choque com a realidade escolar' para vários (doze) estagiários $(2 ; 4 ; 6 ; 10 ; 11 ; 13 ; 14 ; 15 ; 17 ; 18 ; 19$ e 20). Segundo Onofre e Fialho (1995), o choque como real é uma expressão utilizada para se referir à situação pela qual passam os professores no seu primeiro contato com a docência, quando as dificuldades/problemas vividos assumem uma dimensão assustadora, isto é, ocorre um distanciamento entre o ideal e a realidade cotidiana. Já Krug e Krug (2012) destacam que se acontece o choque com a realidade escolar com os professores iniciantes isso também é uma situação vivenciada pelos acadêmicos em situação de estágio. E, nesse direcionamento de ideia citamos Pimenta e Lima (2004), que afirmam que um dos primeiros impactos sofridos pelos estagiários é o susto diante das reais condições das escolas e as contradições entre o escrito e o vivido, o dito pelos discursos oficiais e o que realmente acontece.

Assim, a partir de todo este quadro anteriormente descrito, pelas narrativas escritas sobre a primeira aula ministrada na escola, podemos inferir que doze estagiários $(2 ; 4 ; 6 ; 10 ; 11 ; 13 ; 14 ; 15 ; 17 ; 18 ; 19$ e 20$)$, sem dúvida alguma, estão na fase de sobrevivência do ECS, que segundo Krug e Krug (2012), caracteriza-se pela insegurança provocada pelo choque com a realidade escolar. Os autores destacam que o fato indispensável para sair do choque com a realidade escolar e ir em busca do enfrentamento dessa situação é o estagiário reconhecer-se em dificuldade frente à complexidade da prática, do real.

Neste sentido, podemos constatar que o choque com a realidade escolar, com certeza, já se manifesta para o estagiário desde a primeira aula ministrada. A respeito dessa situação citamos Krug e Krug (2012), que alertam para o fato de que para alguns estagiários o choque com a realidade escolar pode ser tão intenso que mesmo com ajuda (de diversas fontes, tais como: colegas, professor orientador, professor-colaborador, etc.) a superação dessa fase pode não ocorrer. Por isso, torna-se muito importante a sua detecção já na primeira aula ministrada pelo estagiário no intuito de ajudá-lo a mais rapidamente superar este momento.

É conveniente neste momento destacar que este quadro de tensões, dificuldades, medo, insatisfação, crise e choque com o real, durante a docência na primeira aula, acarreta uma grande possibilidade de insucesso pedagógico por parte dos estagiários (2; $4 ; 6 ; 10 ; 11 ; 13 ; 14 ; 15 ; 17 ; 18 ; 19$ e 20) na seqüência das aulas do ECS. 
Entretanto, também, pela análise das narrativas escritas, constatamos que vários (oito) estagiários $(1 ; 3 ; 5 ; 7 ; 8 ; 9 ; 12$ e 16) manifestaram que 'sentiram satisfação' em ter ministrado a sua primeira aula. Segundo Luft (2000), satisfação é uma ação ou efeito de satisfazer-se, é um contentamento, uma alegria. Para Mattos (1994, p.87) a satisfação no trabalho é "um resultado ou conseqüência da experiência do indivíduo que trabalha, na relação com seus valores, isto é, o que ele quer e o que ele espera de seu trabalho".

Eis algumas vozes dos estagiários: "Gostei da minha primeira aula, me senti satisfeito com o desenvolvimento da aula [...]" (Estagiário 1); "Fiquei satisfeito com os alunos na primeira aula [...]" (Estagiário 8); e, "Senti muita satisfação com o resultado da primeira aula [...]" (Estagiário 16).

Assim, com o desenvolvimento dos acontecimentos da primeira aula, alguns (oito) estagiários $(1 ; 3 ; 5 ; 7 ; 8 ; 9 ; 12$ e 16) 'sentiram-se entusiasmados, motivados' para com a sequência da docência no ECS.

Algumas vozes foram as seguintes: "A minha primeira aula foi ótima. Como visava conhecer os alunos foi uma aula solta permitindo que os alunos se mostrassem [...]. A turma gostou, visto que questionaram quando seria a próxima aula e deram demonstração de afeto comigo. Esta situação me deixou satisfeito e entusiasmado com as aulas futuras" (Estagiário 1); "A primeira aula foi tranquila. [...]. Foi boa, os alunos foram participativos e questionadores. Todos saíram da aula realizados e eu muito satisfeito" (Estagiário 3); "A primeira aula foi bastante tranquila, pois os alunos participarem bastante da aula, dando sugestões e executando as atividades propostas. A turma é muito boa e os alunos respeitam-se bastante. Fiquei entusiasmado com o futuro [...]" (Estagiário 5); "Minha primeira aula foi de apresentação aos alunos, procurei fazer brincadeiras já conhecidas pelos alunos. Isto facilitou minha recepção e a aula aconteceu em um clima favorável, o que me deixou motivado para as próximas aulas [...]" (Estagiário 7); "Usando como base as atividades que os alunos gostam de fazer desenvolvi a primeira aula. Os alunos se portaram bem, consegui organiza-los e desenvolver muito bem a aula. Me senti satisfeito com a aula. [...]" (Estagiário 8); "No primeiro dia de aula realizei algumas atividades recreativas para interagir e conhecer os alunos. Ocorreu muito bem. Gostei e me motivei para as outras aulas" (Estagiário 9); “[...]. Foi boa. Os alunos foram participativos, pois realizei as atividades que eles gostavam, assim, pude conhecer melhor os alunos. Fiquei satisfeito com a aula [...]" (Estagiário 12); e, “Minha primeira aula combinei com meus alunos algumas regras. Foi tudo bem na aula. Os alunos me passaram confiança, pois me transmitiram 
entusiasmo na aula e interesse. Isto me deixou entusiasmado, motivado para ir em frente [...]" (Estagiário 16).

A partir destas manifestações, podemos inferir que este quadro de satisfação, entusiasmo e motivação com a docência na primeira aula ministrada acarreta uma grande possibilidade de sucesso pedagógico por parte dos estagiários $(\mathbf{1} ; \mathbf{3} ; \mathbf{5} ; \mathbf{7} ; \mathbf{8} ; \mathbf{9}$; 12 e 16) na sequência das aulas do ECS.

\section{Considerações finais}

Estudarmos alguns acontecimentos do ECS foi fundamental para compreendermos a importância dessa disciplina na formação de futuros professores e, também, para sabermos como essa experiência docente colabora para a formação inicial. Segundo Ilha; Krug e Krug (2009), um estudo dessa natureza é importante porque trás à tona as necessidades, os anseios e as dificuldades encontradas pelos acadêmicos e, em contrapartida, tudo aquilo que de positivo foi para eles descobrirem e construírem.

Assim, pela análise das informações obtidas concluímos que: 1) Quanto ao primeiro dia de escola - a) Todos os (vinte) estagiários foram muito bem recepcionados pela escola; e, b) Quase todos (dezenove) os estagiários foram muito bem recepcionados pelos alunos da turma de estágio na apresentação dos mesmos; e, 2) Quanto ao primeiro dia de aula - a) Todos os (vinte) estagiários tinham boas expectativas de realização de um bom trabalho com os alunos; b) Para doze estagiários surgiu um quadro de choque com a realidade escolar que acarretou preocupações para a sequência das aulas no ECS; e, c) Para oito estagiários surgiu um quadro de satisfação, entusiasmo e motivação para a sequência das aulas no ECS.

Desta forma, o que mais chamou à atenção nos resultados desta investigação foi a constatação de que o processo de inserção dos estagiários na escola constituiu-se num momento de suma importância para o desenvolvimento do ECS, não apenas por ser um período de conhecimento da escola e dos alunos e ainda de aprendizagem docente, mas, sobretudo, pelas implicações dele decorrentes para a formação profissional. Assim, inferimos que, nessa inserção, se o ambiente e as recepções não forem adequados, a tendência é de potencialização das possíveis dificuldades enfrentadas no decorrer do ECS, podendo causar desconforto e sofrimento, desencadeando, inclusive, a vontade de 
não confirmação de ser professor pelo acadêmico. Conforme Krug e Krug (2013), a não confirmação pela docência está ligada às experiências docentes negativas e desprazerosas efetivadas durante o ECS e a confirmação está ligada às experiências positivas e prazerosas.

Para finalizar, sugerimos a realização de investigações mais aprofundadas sobre o processo de inserção dos estagiários nas escolas, pois esse momento é muito importante para a realização de um ECS que contribua para uma formação profissional de qualidade.

\section{REFERÊNCIAS}

ABRAHÃO, M.H.M.B. Pesquisa (auto) biográfica - tempo, memória e narrativa. In: ABRAHÃO, M.H.M.B. (Org.). A aventura biográfica: teoria e empiria. Porto Alegre: EPIPUCRS, 2004.

ALVES, N. Decifrando pergaminhos: o cotidiano das escolas nas lógicas das redes cotidianas. In: OLIVEIRA, I.B.; ALVES, N. (Orgs.). Pesquisa no/do cotidiano das escolas: sobre redes de saberes. Rio de Janeiro: DP\&A, 2001. p.13-38.

ANDRÉ, M.E.D.A. de. Estudo de caso em pesquisa e avaliação educacional. Brasília: Líber Livro Ed., 2005.

BOGDAN, R.C.; BIKLEN, S.K. Investigação qualitativa em educação: uma introdução à teoria e aos métodos. 4. ed. Porto: Porto Editora, 1994.

CEFD. Projeto político-pedagógico, 2005. Disponível em:

<http://www.ufsm.br/cefd/index.php/graduacao/2-uncategorised/86-grade-licenciatura>. Acesso em: 10 jul. 2013.

CUNHA, M.I. Conta-me agora! As narrativas como alternativas pedagógicas na pesquisa e no ensino. Revista da Faculdade de Educação [online], São Paulo, v.23, n.1-2, jan./fev., 1997.

FORTUNATO, I.; CATUNDA, M.; REIGOTA, M. Vozes e memória no/do cotidiano escolar: primeiro dia de escola de futuros professores. Quaestio: Revista de Estudos em Educação, Sorocaba, v.15, n.2, p.339-348, dez., 2013.

ILHA, F.R. da S.; KRUG, R. de R.; KRUG, H.N. A experiência docente na Prática de Ensino/Estágio Curricular Supervisionado em Educação Física dos acadêmicos do CEFD/UFSM (Currículo 1990). Revista Pedagógica, Chapecó: UNOCHAPECÓ, a.11, n.22, p.85-108, jan./jun., 2009.

IVO, A.A.; KRUG, H.N. O Estágio Curricular Supervisionado e a formação do futuro professor de Educação Física. Revista Digital Lecturas: Educación Física y Deportes, Buenos Aires, a.13, n.127, p.1-18, dic., 2008. Disponível em: 
<http://www.efdeportes.com/ed127/a-formacao-do-futuro-professor-de-educacaofisica.htm>. Acesso em: 02 jun. 2014.

JOSSO, M.C. Experiências de vida e formação. Lisboa: Educa, 2002.

KRUG, H.N. A reflexão na prática pedagógica do professor de Educação Física, 1996. Dissertação (Mestrado em Educação Física) - Universidade Federal de Santa Maria, Santa Maria, 1996.

KRUG, H.N. Os fatos marcantes do Estágio Curricular Supervisionado na percepção dos acadêmicos da Licenciatura em Educação Física do CEFD/USM. Revista Digital Lecturas: Educación Física y Deportes, Buenos Aires, a.14, n.142, p.1-15, mar., 2010a. Disponível em: <http://www.efdeportes.com/ed142/estagio-curricularsupervisionado-na-percepcao-dos-academicos.htm>. Acesso em: 24 mai. 2014.

KRUG, H.N. Os problemas/dificuldades na prática pedagógica nos Estágios Curriculares Supervisionados I-II-III na percepção dos acadêmicos da Licenciatura em Educação Física do CEFD/USM. Revista Digital Lecturas: Educación Física y Deportes, Buenos Aires, a.16, n.158, p.1-11, jul., 2011. Disponível em: <http://www.efdeportes.com/ed158/os-problemas-na-pratica-pedagogica-em-educacao> . Acesso em: 27 jun. 2014.

KRUG, H.N. et al. Os dilemas do Estágio Curricular Supervisionado na percepção dos acadêmicos/estagiários da Licenciatura em Educação Física do CEFD/USM. Revista Digital Lecturas: Educación Física y Deportes, Buenos Aires, a.17, n.171, p.1-14, ago., 2012. Disponível em: <http://www.efdeportes.com/ed171/os-dilemas-do-estagiocurricular-supervisionado.htm>. Acesso em: 24 mai. 2014.

KRUG, H.N. et al. Necessidades formativas de acadêmicos de Licenciatura em Educação Física em situação de Estágio Curricular Supervisionado. Revista IberoAmericana de Estudos em Educação, Rio Claro, v.8, n.1, p.252-274, 2013.

KRUG, R. de R.; IVO, A.A.; KRUG, H.N. As lembranças significativas do tempo da Educação Física Escolar na educação básica pelos licenciandos do CEFD/UFSM: colaborando com o "aprender a ser professor". Boletim Brasileiro de Educação Física, Brasília, n.73, p.1-9, 2009. Disponível em:

<http://www.boletimef.org/?canal=12\&file=2174>. Acesso em: 01 jun. 2014.

KRUG, R. de R.; KRUG, H.N. As expectativas e as realizações no Estágio Curricular Supervisionado dos acadêmicos da Licenciatura em Educação Física do CEFD/UFSM. Revista Digital Lecturas: Educación Física y Deportes, Buenos Aires, a.16, n.163, p.1-9, dic., 2011. Disponível em: <http://www.efdeportes.com/ed163/as-expectativasno-estagio-curricular-supervisionado > Acesso em: 02 jul. 2014.

KRUG, R. de R.; KRUG, H.N. Os percursos de trans-formações de licenciandos em Educação Física: as percepções sobre as fases do Estágio Curricular Supervisionado. Revista Digital Lecturas: Educación Física y Deportes, Buenos Aires, a.17, n.172, p.1-16, mar., 2012. Disponível em: <http://www.efdeportes.com/ed172/transformacoes-de-licenciandos-em-educacao-física>. Acesso em: 24 mai. 2014. 
KRUG, R. de R.; KRUG, H.N. Os Estágios Curriculares Supervisionados I-II-III na Licenciatura do CEFD/UFSM: a confirmação ou não do ser professor de Educação Física... na escola. Revista Formação@Docente, Belo Horizonte, v.5, n.2, p.34-45, 2013.

LUFT, C.P. MiniDicionário Luft. 6. ed. São Paulo: Ática/Scipione, 2000.

MARCELLOS, V.A. Relações interpessoais - reflexões a cerca do cotidiano escolar. Artigonal - Diretório de Artigos Gratuitos, 2009.

MARQUES, M.N.; ILHA, F.R. da S.; KRUG, H.N. O acadêmico da Licenciatura em Educação Física do CEFD/UFSM em situação de estágio: aprendizagem, desenvolvimento e contribuições deixadas aos escolares. Boletim Brasileiro de Educação Física, Brasília, n.74, p.1-11, mai./jun., 2009. Disponível em: $<$ http://www.boletimef.org/biblioteca/2296/O-academico-de-Educacao-Física-doCEFD/UFSM-em-situacao-de-estagio>. Acesso em: 02 jun. 2014.

MARQUES, M.N.; KRUG, H.N. Os aspectos positivos e negativos sentidos pelos acadêmicos de Educação Física do CEFD/UFSM durante a realização do Estágio Curricular Supervisionado. Revista Digital Lecturas: Educación Física y Deportes, Buenos Aires, a.15, n.147, p.1-6, ago., 2010. Disponível em: $<$ http://www.efdeportes.com/ed147/aspectos-positivos-do-estagio-curricularsupervisionado.htm>. Acesso em: 02 jun. 2014.

MATTOS, M.G. de. Vida no trabalho e sofrimento mental do professor de Educação Física na escola municipal: implicações em seu desenvolvimento e na sua vida profissional, 1994. Tese (Doutorado em Administração Escolar) - Universidade de São Paulo, São Paulo, 1994.

MIRANDA, M.I. Ensino e pesquisa: o estágio como espaço de articulação. In: SILVA, L.C.; MIRANDA, M.I. (Orgs.). Estágio Supervisionado e Prática de Ensino: desafios e possibilidades. Araraquara: Junqueira \& Marin/Belo Horizonte: FAPEMIG, 2008. p.15-36.

MOITA, M. da C. Percursos de formação e de trans-formação. In: NÓVOA, A. (Org.). Vidas de professores. Porto: Porto Editora, 1992.

OLIVEIRA, V.F. de. Narrativas e saberes docentes. In: OLIVEIRA, V.F. de (Org.). Narrativas e saberes docentes. Ijuí: UNIJUÍ, 2006.

ONOFRE, M.S.; FIALHO, M. Diagnóstico dos problemas da prática pedagógica em Educação Física: o caso dos professores estagiários. In: CONGRESSO DE EDUCAÇÃO FÍSICA E CIÊNCIAS DO DESPORTO DOS PAÍSES DE LÍNGUA PORTUGUESA, IV, 1995, Coimbra. Anais, Coimbra: Universidade de Coimbra, 1995. p.EF-45.

PANIZ, C.M. O diário da prática pedagógica e a construção da reflexividade na formação inicial de professores de Ciências Biológicas da UFSM, 2006. Dissertação (Mestrado em Educação) - Universidade Federal de Santa Maria, Santa Maria, 2006. 
PIMENTA, S.G.; LIMA, M.S.L. Estágio e docência. São Paulo: Cortez, 2004.

REIGOTA, M. Ecologistas. Santa Cruz do Sul: EDUNISC, 1999.

SILVA, M.S. da; KRUG, H.N. A Educação Física Escolar no ensino fundamental na região central do RS: a opinião do aluno. In: HENTGES, A. et al. (Orgs.). Construindo práticas educativas interdisciplinares. Cruz Alta: UNICRUZ, 2005.

\section{Como referenciar este artigo}

KRUG, Hugo Norberto. Vozes e memória no/do cotidiano escolar: o primeiro dia de escola e de aula de acadêmicos de educação física em situação de estágio curricular supervisionado. Revista Ibero-Americana de Estudos em Educação, Araraquara/SP, v. $11, \quad$ n. $3, \quad$ p.1539-1556, 2016. Disponível em: <https://dx.doi.org/10.21723/riaee.v11.n3.7110>. E-ISSN: 1982-5587.

Submetido em: 20/07/2014

Aprovação final em: 11/07/2016 